\title{
Sediment transport monitoring in a Northern Puglia watershed
}

\author{
F. Gentile, T. Bisantino, R. Corbino, F. Milillo, G. Romano \\ \& G. Trisorio Liuzzi \\ PROGESA Department, University of Bari, Bari, Italy
}

\begin{abstract}
The main torrents in Northern Apulia (Southern Italy) are characterised by a considerable suspended sediment transport that occurs during intense rainfall events. In this paper an experimental activity of sediment transport monitoring is described. A continuous measuring station located in the Carapelle torrent is equipped with a dual function optical immersion probe (turbidity/sediment). The probe has been tested with laboratory and field experiments carried out to verify the instrument's functional capabilities and to assess the relationship between optical and gravimetric data. Monitored data have then been used to analyze the sediment transport at event scale in view to estimate the sediment balance in the watershed.
\end{abstract}

Keywords: continuous river monitoring, sediment transport, turbidimeter.

\section{Introduction}

The sediment transport processes that affect the torrents originating from Subappennino dauno and crossing the alluvial valley of Tavoliere are mainly characterised by suspended materials. The Hydrological Service of Apulia Region measured the suspended load of these water courses during the period 1933-1989. After 1989 the monitoring system was interrupted.

In these torrents Marchi et al [1] found a close correlation between discharges and sediment loads. This is quite consistent with what observed by other authors who showed that the most of the annual suspended sediment is transported during the flood events, Walling et al [2]. During flood events the relationship between the suspended sediment concentration and the discharge is not linear 
and often presents a hysteretic loop. Analyzing the shapes of such relationships it is possible to identify the sediment sources, Williams [3], Lenzi and Marchi [4].

To accurately estimate the sediment transport during floods it is necessary to sample frequently or to set up a continuous measuring system, Lewis [5], Lewis [6]. Based on such considerations an experimental station was set up to measure the suspended sediment transport in the Carapelle stream (Basin area: $506 \mathrm{~km}^{2}$ ). This station is equipped with a remote data transmission, ultrasound stage meter and a stage recorder. In addition, an infrared optic probe has been set up for the continuous measurement of the suspended sediment concentration, Bisantino et al [7].

The probe was preliminary tested in laboratory using mixtures of varying granulometric concentration to evaluate its functional capacity and to assess the effects of the different solid fractions on the measurements, Gentile et al [8]. Afterwards, the instrument was tested in the field through a calibration stage and the verification of the instrument housing. The most relevant flood events were then considered and the suspended sediment concentration, monitored at halfhourly scale, was plotted versus discharge to analyze the sediment transport dynamic.

\section{Experimental station measuring suspended sediment concentration}

The experimental station measuring suspended sediment concentration is located in the Carapelle torrent (at Ordona-Castelluccio Dei Sauri bridge), one of the main in Northern Apulia, fig. 1, tab.1. The torrent originates in the Apennine mountains and crosses the Tavoliere flood plain before flowing into the Adriatic

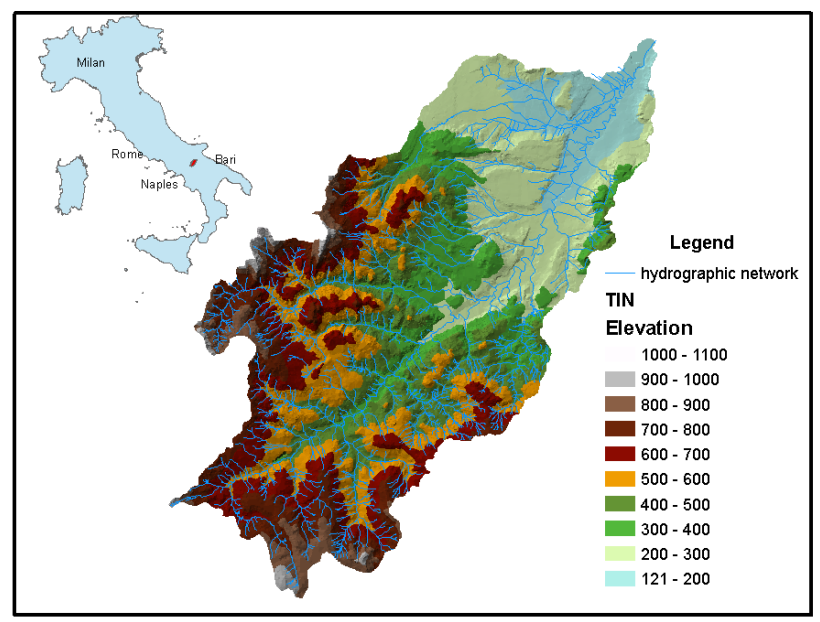

Figure 1: The Carapelle watershed with mouth at the sediment transport experimental station. 
Table 1: $\quad$ Main characteristics of the Carapelle watershed.

\begin{tabular}{l|ll}
\hline Watershed area & $\mathrm{A}$ & $506.2 \mathrm{~km}^{2}$ \\
Average altitude & $\mathrm{H}_{\mathrm{m}}$ & $466 \mathrm{~m}$ a.s.1. \\
Main channel length & $\mathrm{L}$ & $52.16 \mathrm{~km}$ \\
Main channel slope & $\mathrm{i}_{\mathrm{c}}$ & $16.3 \%$ \\
Mean watershed slope & $\mathrm{i}_{\mathrm{w}}$ & $8.2 \%$ \\
\hline
\end{tabular}

sea. The watershed is characterised by clayey-sandy Plio-Pleistocene sediments in the alluvial fan and by flyschoid formations in the mountainous areas, which are subject to erosion. The plain and the low hilly areas are mainly used for olive growing, whereas the higher slopes are occupied by woods and pasture. The climate is typically Mediterranean, with rainfalls ranging from 450 to 800 $\mathrm{mm} /$ year and average temperatures ranging from 10 to $16^{\circ} \mathrm{C}$.

The experimental sediment transport station is equipped with an infrared optical probe (Hach-Lange SOLITAX Hs-line), chosen in view of its sensitivity to the grain size distribution of the particles that characterise the suspended material. The probe has a dual function: it measures turbidity, when only the nephelometric photodetector is active, or suspended sediment when the backscattering photodetector also works.

The instrument is housed in a tube to protect it from the impact of any flowing coarse material and from any potential measuring errors caused by incident radiant energy straying into the infrared field, fig. 2.

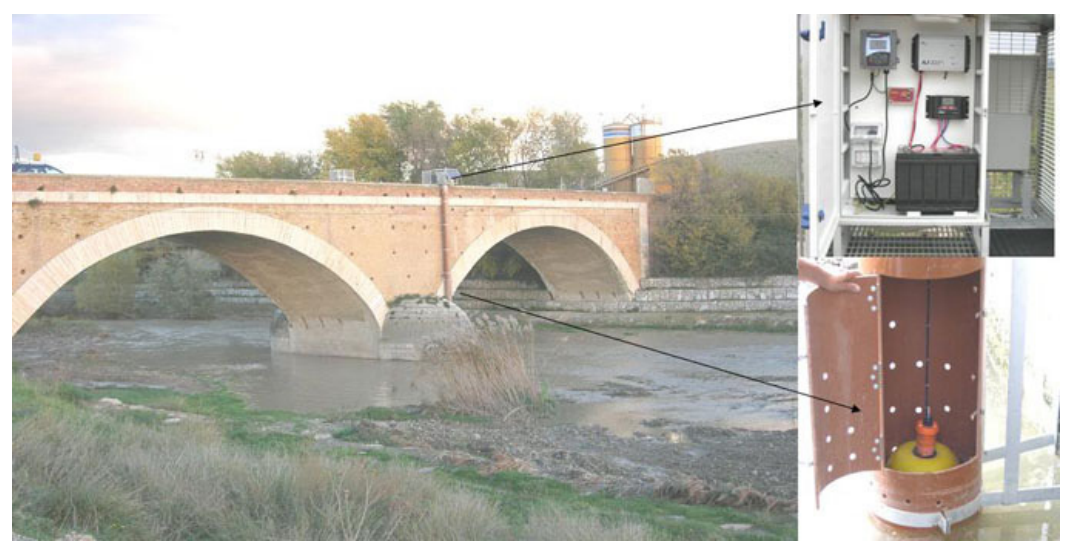

Figure 2: $\quad$ Sediment transport measuring station, optical probe housing and data acquisition system.

\section{Functional characteristics of the optical probe: laboratory testing stage}

During the experimental laboratory phase, the instrument was checked to evaluate its functionality in the two operating modes (turbidity and suspended 
sediment), both in homogenous granulometric mixtures and varying ratios between sandy and fine fraction. The instrument was analysed using a heterogeneous sample of material taken from the riverbed of the Carapelle stream. The material contained $87.5 \%$ of sand, $8.8 \%$ of silt and $3.7 \%$ of clay. The probe was fixed into an electromagnetic stirrer while Imhoff cones were used to separate the sediment fractions from the mixtures, fig. 3.

During the first stage, the material was divided into two samples: the first sample was oven-dried and used to make up 20 mixtures of homogeneous granulometry, in a set range of concentrations. The second sample, kept in naturally wet conditions, was used to make up 11 mixtures in which the concentrations were not predefined, although they were later established through a gravimetrical method. During the second stage the material was sifted $(d=0.063$ $\mathrm{mm}$ - UNI, BS Standards) to separate the sand fraction from the fine one (silt and clay) and used to prepare 36 mixtures of known concentration but different granulometric composition.

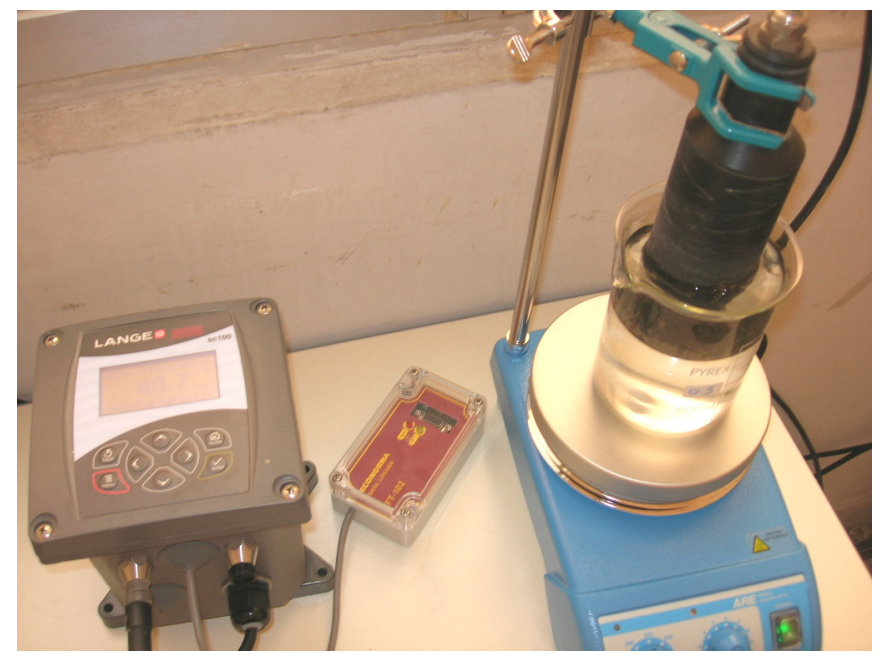

Figure 3: Laboratory equipment.

Using the probe in turbidity mode (single photo detector), a blindness effect has been observed (I stage) and, for very fine sediment, this effect occurs also for low sediment concentrations (II stage). In suspended sediment mode (ratio detection system) a first order relationship between measured and observed data was achieved (I stage); the curve slope increases with the fine fraction (II stage), fig. 4.

This result allows one to use a unique conversion factor for mixtures having the same grain size and different sediment concentrations. The results of this experimental phase have shown that, for the measurement of the suspended sediment transport, a combined system of photodetectors should be preferred. Measurements made with only one single photo detector are imprecise and nonlinear due to the beam reduction process. 
I STAGE

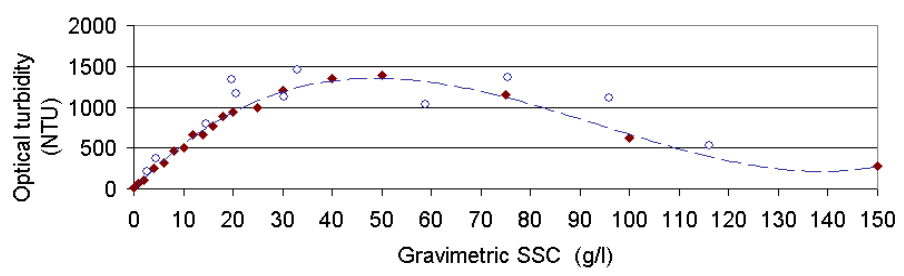

- Dry base mixtures o Wet base mixtures - -
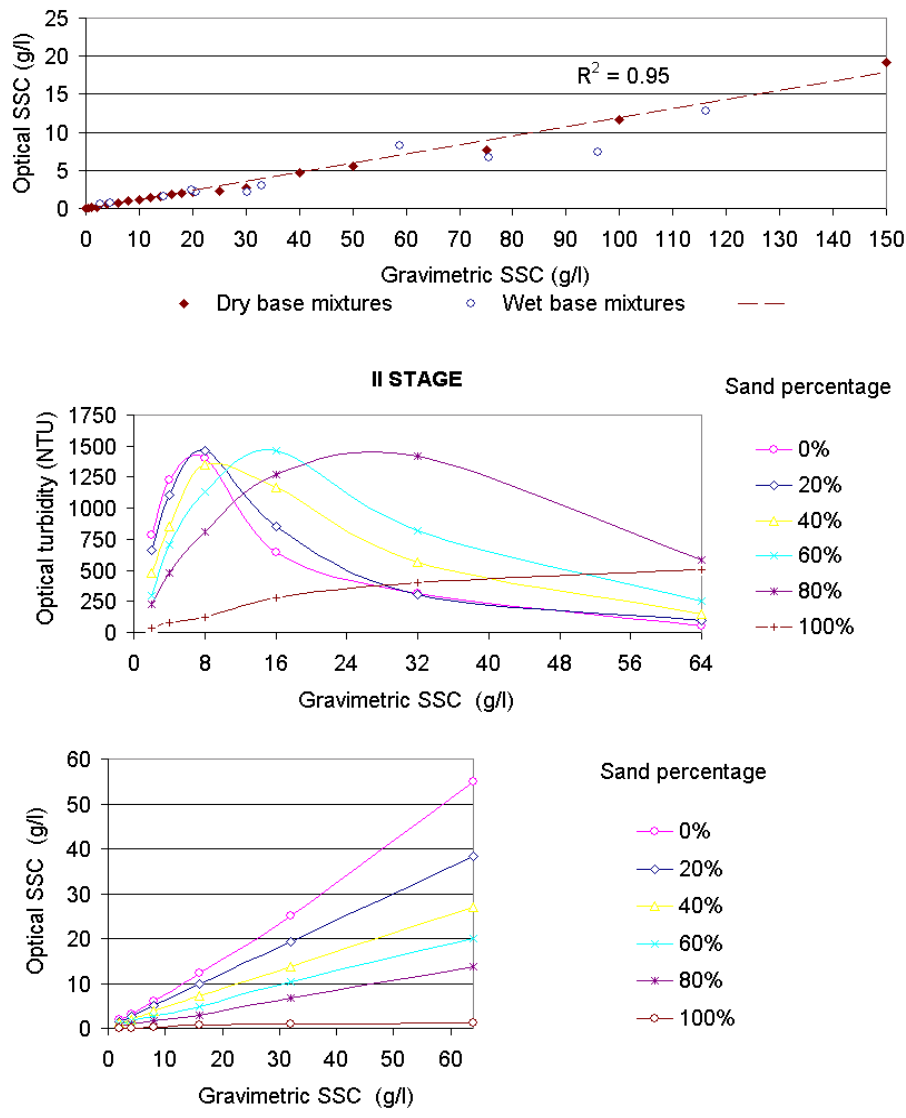

Sand percentage

$-\infty 0 \%$

$\neg-20 \%$

$-40 \%$

$-60 \%$

* $-80 \%$

$-\infty 100 \%$

Figure 4: Results of the laboratory experimental stages: existing relationships between the optical and the gravimetric data.

\section{Field calibration stage}

The instrument field testing was carried out in order to validate the results obtained during the laboratory study and, in particular, to confirm the existence of a linear relationship between the data measured by the instrument and the 
gravimetric data. Eight flood events were monitored and 65 turbid samples were collected using the "Magistrato" sampler, fig. 5. The instrument belongs to the "thief sampler" category, Holmes et al [9], and consists of a horizontal Van Dorn bottle closed by a float mechanism.

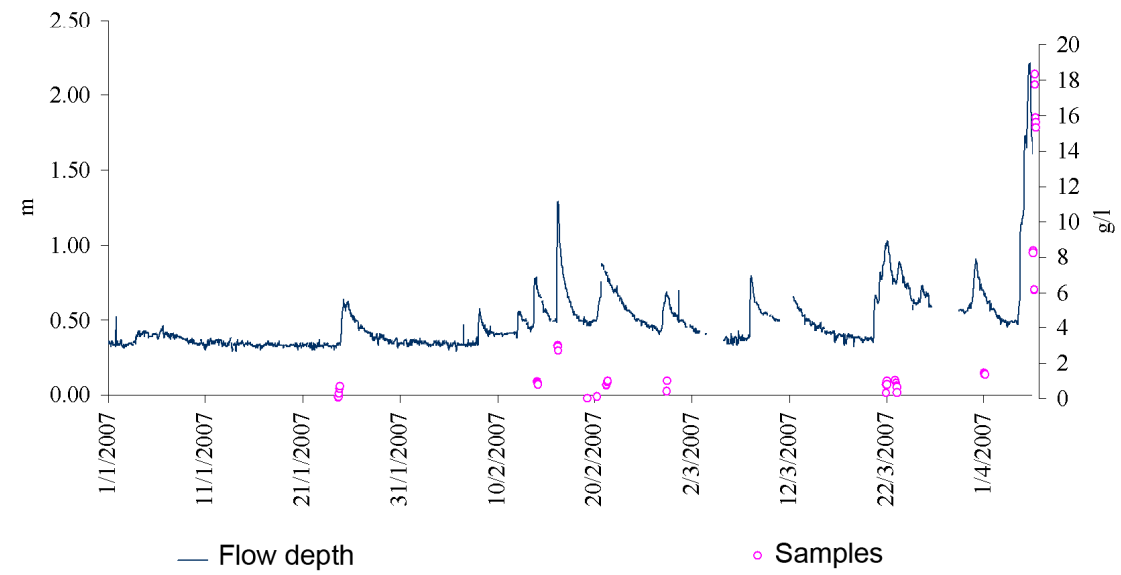

Figure 5: $\quad$ Flow depth series and suspended sediments concentrations of the samples collected in the Carapelle stream during the 2006-2007 season.

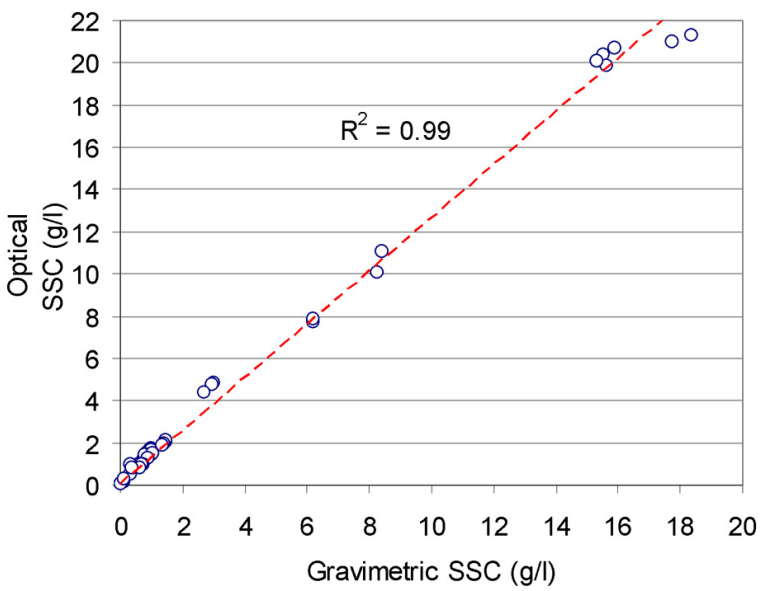

Figure 6: Linear relationship existing between the optical suspended sediment concentration (SSC) measured in field and the gravimetric data.

Seventeen pairs of samples were taken outside and inside the tube in order to check the instrument lodging. Their sediment samples were then compared to evaluate the occurrence of any alterations caused by the protective tube. The external concentrations proved to be equal to the internal ones $\left(\mathrm{R}^{2}=1\right)$, and the 
samples taken from both positions have been considered as part of the dataset used during the calibration stage.

The samples collected during the flood events mainly consisted of fine materials: the first 28 samples, joined together, contained $9.4 \%$ of sand, $32.9 \%$ of silt and $57.7 \%$ of clay.

The sediment concentrations of all the samples proved to be correlated with the data measured by the instrument, as shown in figure 6 . In the range of the monitored discharges the results confirmed the existence of a linear relationship between the gravimetric and the optical data.

\section{Analysis of flood events}

During the monitoring season, four significant events, having continuous data and absence of anomalies in the time series, have been selected. The data, registered at half-hourly scale, have been used to analyze the relationships, existing during the flood events, between the sediment concentration (SSC) and the discharge $\left(\mathrm{Q}_{1}\right)$. The results underline the existence of a hysteretic loop between sediment concentration and discharge, as shown in figure 7.

The loop-shaped curves, existing between SSC and $\mathrm{Q}_{1}$, depend on the sediment availability that derives from sediment supply and/or from possible sediment deposits, Williams [3].

In the clockwise loop a rapid increase of the suspended sediment at the beginning of the flood event occurs for the presence of available sediment in the water course. If the sediment concentration decreases before the falling limb of the hydrograph, the sediment source areas can be considered limited. In the counterclockwise loop, instead, the sediment source areas are mainly located on hill slopes and the material moves slower than the peak discharge, Lenzi and Marchi [4].

In the first three events the sediment concentration decreases after the peak discharge (counterclockwise loop). This behaviour can be explained in terms of distance crossed by the sediment up to the measuring station during the events, Brasington and Richards [10].

The most intense event, that of April 5, is instead characterized by a clockwise loop. The advance of the sediment concentration peak can be explained because the sediment availability decreases during the event. This type of loop frequently occurs at the end of the rainy season and it is influenced by the availability of the sediments produced by the previous floods, Campbell [11].

The rate of transport changes from the falling limb to the rising limb of the hydrographs and this effect is induced by the unsteadiness of the flow, De Sutter et al [12].

\section{Conclusions}

In this paper the results of sediment transport monitoring study in a Northern Apulia torrent are reported. The adopted instrument is an optical immersion probe which measures the turbidity or the concentration of suspended solids. 

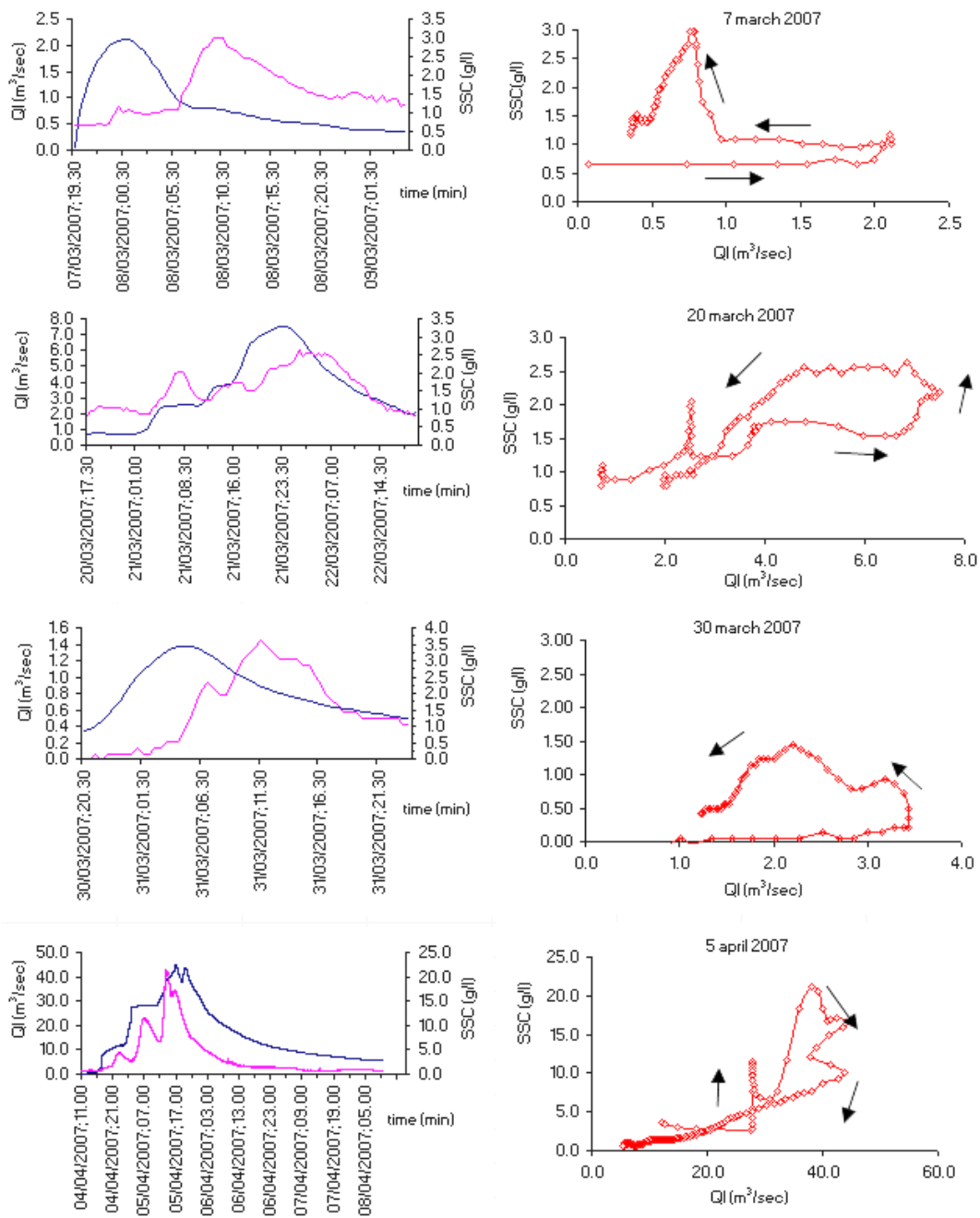

Figure 7: Relationships between the suspended sediment concentration (SSC) and the discharge $\left(\mathrm{Q}_{1}\right)$ during four significant flood events in the Carapelle stream.

The instrument was laboratory tested and the results showed that a combined photodetector system produced the best results, because a linear relationship between the optical and the gravimetric data was observed. Furthermore, with equal levels of concentration, the measurement tended to increase together with the fine fraction.

The field testing stage confirmed the results achieved in the laboratory, evidencing the linear relationship between the optical measurement of solid sediment transport and the gravimetric data measured on the turbidity samples. The instrument housing did not interfere the measuring process. 
Four flood events were analysed to investigate the relationship between suspended sediment (SSC) concentration and discharge $\left(Q_{1}\right)$ in unsteady flows. The SSC- $\mathrm{Q}_{1}$ curves revealed that in the Carapelle stream both the clockwise and counterclockwise loops are possible and can be related to the event intensity and to the sediment supply.

\section{References}

[1] Marchi, L., Trisorio-Liuzzi, \& G., Zanframundo, P., Analisi dei deflussi torbidi nei piccoli bacini del Sub- Appennino dauno. Quaderni di Idronomia Montana, 6:95-121, 1986.

[2] Walling, D.E., Webb, B.W., \& Woodward, J.C., Some sampling considerations in the design of effective strategies for monitoring sedimentassociated transport. IAHS Spec. Publ. 210, 279-288, 1992.

[3] Williams, G.P., Sediment concentration versus water discharge during single hydrologic events in rivers. Journal of Hydrology 111:89-106, 1989.

[4] Lenzi, M. A., \& Marchi, L., Suspended sediment load during floods in a small stream of the Dolomites northeastern Italy. Catena 39: 267-282, 2000.

[5] Lewis, J., Turbidity-controlled suspended sediment sampling for runoffevent load estimation. Water Resour. Res. 32(7): 2299-2310, 1996.

[6] Lewis, J., Turbidity-controlled sampling for suspended sediment load estimation. In: Bogen, J. Tharan Fergus and Des Walling (eds.), Erosion and Sediment Transport Measurement in Rivers: Technological and Methodological Advances (Proc. Oslo Workshop, 19-20 June 2002). IAHS Publ. 283: 13-20, 2003.

[7] Bisantino, T., Corbino, R., Gentile, F., Grittani, A., Milillo, F., Romano, G., Trisorio Liuzzi, G., \& Zanframundo, P., Monitoraggio del trasporto solido nei bacini della Puglia settentrionale tra il Candelaro e l'Ofanto. Quaderni di Idronomia Montana 26: 193-204, 2006.

[8] Gentile, F., Bisantino, T., Milillo, F., Romano, G., \& Trisorio Liuzzi, G., Caratteristiche funzionali di una sonda a raggi infrarossi per la misura del trasporto solido in sospensione nei corsi d'acqua. Quaderni di Idronomia Montana 27:421-432, 2007.

[9] Holmes, R. R., Jr., Terrio, P. J., Harris, M. A., \& Mills, P. C., Introduction to field methods for hydrologic and environmental studies. U.S. Geological Survey, Open-File Report 01-50, Urbana, Illinois, 245 pp. http://onlinepubs.er.usgs.gov/djvu/OFR/2001/ofr_01_50.djvu, 2001.

[10] Brasington, J., \& Richards, K., Turbidity and suspended sediment dynamics in small catchments in the Nepal Middle Hills. Hydrol. Process. 14: 2559 2574, 2000.

[11] Campbell, G. S., Soil Physics with Basic Transport Models for Soil-Plant Systems. Developments in Soil Science 14, Elsevier New York, 1985

[12] De Sutter, R., Verhoeven, R., \& Krein, A., Simulation of sediment transport during flood events: laboratory work and field experiment. Hydrol. Sc. 46(4): 599-610, 2001. 